\title{
Article \\ Opportunities and Barriers of Telemedicine in Rheumatology: A Participatory, Mixed-Methods Study
}

\author{
Felix Muehlensiepen ${ }^{1,2,3,4, *(\infty)}$, Johannes Knitza ${ }^{4,5,6}{ }^{(}$, Wenke Marquardt ${ }^{1}$, Susann May ${ }^{2}$, Martin Krusche ${ }^{7}$, \\ Axel Hueber ${ }^{8}{ }^{\circ}$, Julian Schwarz ${ }^{9}$, Nicolas Vuillerme ${ }^{4,10,11} \mathbb{D}$, Martin Heinze ${ }^{2,3,9}$ and Martin Welcker ${ }^{12}$
}

check for updates

Citation: Muehlensiepen, F.; Knitza, J.; Marquardt, W.; May, S.; Krusche, M.; Hueber, A.; Schwarz, J.; Vuillerme, N.; Heinze, M.; Welcker, M. Opportunities and Barriers of Telemedicine in Rheumatology: A Participatory, Mixed-Methods Study. Int. J. Environ. Res. Public Health 2021, 18, 13127. https://doi.org/10.3390/ ijerph182413127

Academic Editors: Sabrina Cipolletta, Diana Castilla, Carlos Suso-Ribera and Paul B. Tchounwou

Received: 13 October 2021

Accepted: 9 December 2021

Published: 13 December 2021

Publisher's Note: MDPI stays neutral with regard to jurisdictional claims in published maps and institutional affiliations.

Copyright: (c) 2021 by the authors. Licensee MDPI, Basel, Switzerland. This article is an open access article distributed under the terms and conditions of the Creative Commons Attribution (CC BY) license (https:// creativecommons.org/licenses/by/ $4.0 /)$.
1 KV Consult-und Managementgesellschaft mbH, 14469 Potsdam, Germany; wenke.marquardt@gmx.de

2 Center for Health Services Research, Brandenburg Medical School Theodor Fontane, 15562 Rüdersdorf bei Berlin, Germany; Susann.May@mhb-fontane.de (S.M.); martin.heinze@immanuelalbertinen.de (M.H.)

3 Faculty of Health Sciences Brandenburg, Brandenburg Medical School Theodor Fontane, 16816 Neuruppin, Germany

4 AGEIS, Université Grenoble Alpes, 38000 Grenoble, France; Johannes.Knitza@uk-erlangen.de (J.K.); nicolas.vuillerme@univ-grenoble-alpes.fr (N.V.)

5 Department of Internal Medicine 3-Rheumatology and Immunology, Friedrich-Alexander University Erlangen-Nürnberg and Universitätsklinikum Erlangen, 91054 Erlangen, Germany

6 Deutsches Zentrum für Immuntherapie, Friedrich-Alexander University Erlangen-Nürnberg and Universitätsklinikum Erlangen, 91054 Erlangen, Germany

7 Department of Internal Medicine III, University Medical Center Hamburg-Eppendorf, 20251 Hamburg, Germany; m.krusche@uke.de

8 Division of Rheumatology, Klinikum Nürnberg, Paracelsus Medical University, 90419 Nürnberg, Germany; axel.hueber@fau.de

9 Department of Psychiatry and Psychotherapy, Brandenburg Medical School Theodor Fontane, Immanuel Klinik Rüdersdorf, 15562 Rüdersdorf, Germany; Julian.Schwarz@mhb-fontane.de

10 Institut Universitaire de France, 75006 Paris, France

11 LabCom Telecom4Health, Orange Labs \& Université Grenoble Alpes, CNRS, Inria, Grenoble INP-UGA, 38400 Grenoble, France

12 Medizinisches Versorgungszentrum für Rheumatologie Dr. M. Welcker GmbH, 82152 Planegg, Germany; Martin.Welcker@rheumatologie-welcker.de

* Correspondence: felix.muehlensiepen@mhb-fontane.de

Abstract: Despite all its promises, telemedicine is still not widely implemented in the care of rheumatic and musculoskeletal diseases (RMDs). The aim of this study is to investigate opportunities, barriers, acceptance, and preferences concerning telemedicine among RMD patients and professional stakeholders. From November 2017 to December 2019, a participatory, mixed-methods study was conducted, consisting of (1) expert interviews $(n=27)$ with RMD patients and professional stakeholders, (2) a national paper-based patient survey $(n=766)$, and (3) focus groups $(n=2)$ with patient representatives and rheumatologists. The qualitative findings indicate that patients equate personal contact with physical face-to-face contact, which could be reduced by implementing telemedicine, thus negatively influencing the patient-doctor relationship. Correspondingly "no personal contact with the doctor" is the main reason (64\%) why $38 \%$ of the surveyed patients refuse to try telemedicine. Professional stakeholders expect telemedicine to contribute to the effective allocation of scarce resources in rheumatology care. The main barriers reported by stakeholders were the scarcity of time resources in RMD care, the absence of physical examinations, and organizational challenges associated with the implementation of telemedicine in RMD care. While the exact integration of telemedicine into routine care has yet to be found, the consequences on the patient-physician relationship must be permanently considered.

Keywords: chronic disease; rheumatology; telemedicine; eHealth; mHealth; patient perspective; mixed methods; qualitative research; survey 


\section{Introduction}

The global burden of rheumatic and musculoskeletal diseases (RMDs) is rising [1]. While increasingly effective treatments are being developed, the number of newly registered rheumatologists is stagnating [2] and the global demand for rheumatologists is not being met [3]. The deficit of rheumatologists has led to diagnostic delays in many diseases [4] and a decline in treatment effectiveness [5]. In recent decades, information and communication technologies have entered health care [6-11] with telemedicine as one promising field of application.

"[T]he practice of medicine over a distance, in which interventions, diagnoses, therapeutic decisions, and subsequent treatment recommendations are based on patient data, documents and other information transmitted through telecommunication systems" [12].

Opportunities of telemedicine are numerous [13] and have been demonstrated in multiple medical domains [14], an example of which is cardiology care: Telemedicine support may help to overcome diagnostic delays [15] and even reduce mortality in heart failure [16]. Furthermore, telemedicine can increase the efficiency of health care, shorten travel distances, facilitate access to health care services [17], and thus might reduce socioeconomic barriers [18] — aspects that are also discussed as potentials of telemedicine in rheumatology care (telerheumatology) [19-22].

Despite these promises, telemedicine is still not widely implemented in RMD care [23]. In Germany, infrastructural and regulatory barriers, in particular, have prevented the comprehensive implementation of telemedicine in rheumatology and beyond [21,23]. To reduce these barriers and boost digital transformation, the German Bundestag passed the Digital Health Care Act in November 2019 [24]. Shortly after its release, COVID-19 hit health care systems worldwide, leading to dramatic changes in health care delivery. Telemedicine thus became a necessity to reduce the number of contacts and control transmission, leading to an upturn in the use [25] and acceptance of telemedicine services in Germany [21,26]. This was initially reflected in a massive increase in the volume of telemedicine services billed by medical practices in Germany [27]. Since the beginning of 2021, however, these figures have been declining again [27]. Persistent barriers seem to hinder the sustainable implementation of telemedicine.

The aim of this mixed-methods study was to investigate opportunities, barriers, acceptance, and preferences concerning telemedicine among patients with RMD and professional stakeholders involved in RMD patient management based on pre-COVID-19 data.

\section{Materials and Methods}

\subsection{Study Design}

To explore opportunities and barriers of telerheumatology implementation, an exploratory, participatory, mixed-methods study design [28] was used (Figure 1). It consists of complementary data from (1) expert interviews with patients and professional stakeholders in rheumatology care, (2) a national, paper-based RMD patient survey, and (3) patient and rheumatologist focus groups. Data were collected, analyzed, and interrelated in an iterative process.

The study was conducted in compliance with current data protection regulations and the Helsinki Declaration in its current form [29]. All study participants were informed about the research project. Participants of the qualitative research provided written consent. According to the ethics committee of Brandenburg Medical School, no written consent was required from the survey participants due to the non-interventional approach.

\subsection{Expert Interviews}

To explore telemedicine concepts and perspectives and map the complexity of rheumatology care, expert interviews [30] were conducted. Participants were selected using purposive sampling criteria [31]. Inclusion criteria covered engagement in German rheumatology care-namely, patients (members of the patient organization Deutsche Rheuma-Liga), 
providers, digital health developers, or, in order to reflect regulative and administrative aspects, representatives of the German health insurance system. The exclusion criterion was no engagement in German rheumatology care. Interviewees were initially recruited via snowball sampling and later via direct approach by two health scientists (F.M. and W.M.). Eligibility was verified prior to the interview as part of the scheduling of the interview by telephone. The interview guide (Supplementary Table S1) was designed by F.M. and W.M. based on research literature and focused on challenges and potentials to improve RMD care, as well as perception and experience with telemedicine. In addition, socio-demographic data were collected on gender, age, and job position. The interview guide was piloted in two interviews. It was found that the guide was applicable and only minor editorial adjustments were necessary. Thus, the data from the pilot interviews (1 and 2) were included in the analysis The interviews were conducted face to face $(n=23)$ or via telephone $(n=4)$ in case of long distances. Interviews were conducted from November 2017 to July 2019 by F.M. and W.M.

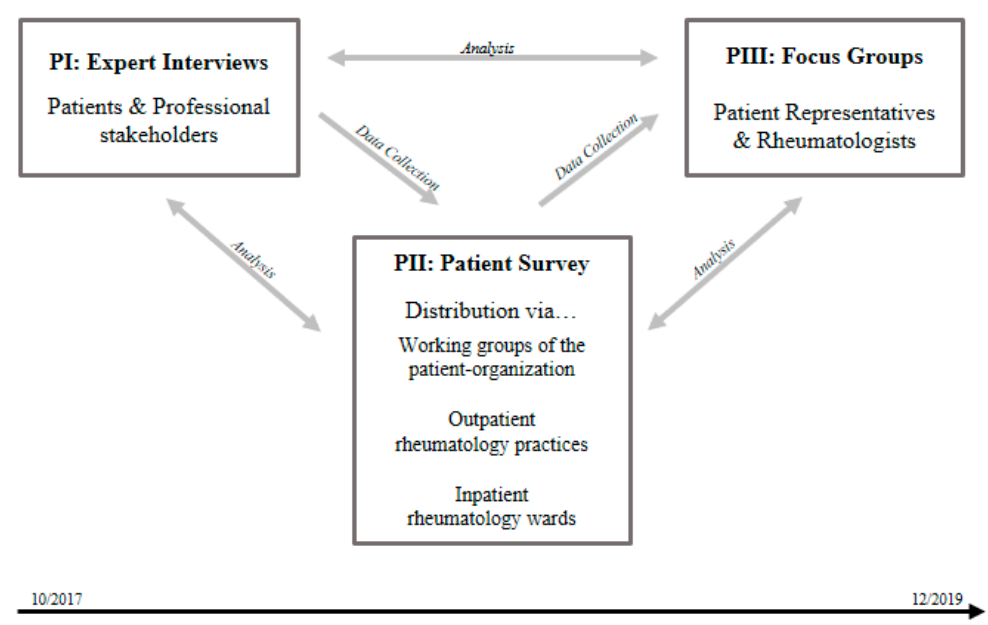

Figure 1. Mixed-methods study design.

\subsection{Patient Survey}

In the first step, two health care researchers (F.M. and W.M.) and two rheumatologists (M.W., J.K.) designed the first draft of the questionnaire based on the results of the expert interviews. In the second step, the draft was sent to the office of the German League against Rheumatism (Deutsche Rheuma-Liga, Landesvertretung Brandenburg e.V.) for review and modification. The comments of the patient representatives were discussed in a telephone conference and adopted. In the third step, the questionnaire was pretested on $30 \mathrm{RMD}$ patients to gauge the need to refine wording and format and check whether predefined response options were exhaustive. Minor revisions were made accordingly. The final fivepage questionnaire comprised 24 questions, divided into 4 mandatory sections: (1) medical care; (2) technology usage; (3) telemedicine; (4) personal data. Response categories were nominal or ordinal. The questionnaire also contained open questions. The questionnaire was complemented by study information, including a definition of telemedicine with two examples: "Telemedicine refers to the use of information and communication technology in medical treatment to overcome spatial distances. Example 1: Video consultation with physician for visual joint check. Example 2: Phone call with the doctor to check the effectiveness of medication." (Translation from German). The inclusion criteria for the survey were being (1) a patient in rheumatology care; (2) $\geq 18$ years; (3) in Germany. Sampling was based on a non-probability, voluntary approach by involving (1) working groups of the patient organization German League against Rheumatism; (2) outpatient rheumatology practices; (3) inpatient rheumatology wards. The questionnaires were administered to representatives of the aforementioned institutions, in order to hand out the questionnaires to potential participants who met the inclusion criteria. 
The survey was carried out between 1 September and 30 December 2019. Stamped envelopes were enclosed with the questionnaires for return to the study center, where the completed questionnaires were entered into SPSS Windows version 22.0 (IBM Corp., Armonk, NY, USA). The analysis included descriptive statistics: quantities, percentages, as well as median scores, and ranges for ordinal variables.

\subsection{Focus Groups}

Focus groups [32] were conducted on the topic "Telemedicine in Rheumatology". The aim of the two discussions was the joint interpretation, critical appraisal, and feedback on the survey results. The first focus group was held in September 2019 with rheumatologists of the Young Rheumatology Working Group of the German Society of Rheumatology (DGRh) in September 2019. The second focus group occurred in November 2019 with patient representatives of the German Rheumatism League.

The inclusion criteria for the focus groups were being (1) in rheumatology care in Germany or (2) a practicing rheumatologist. Individuals who did not meet these criteria were excluded from the focus groups. The discussion was stimulated by presentation slides with survey results and the request to interpret the findings.

\subsection{Qualitative Content Analysis}

The qualitative data, both the expert interviews and focus groups, were audio recorded and transcribed verbatim. Initially, data collection and analysis were performed iteratively by two health scientists (F.M. and W.M.) using Kuckartz's structured qualitative content analysis [33] supported by MAXQDA Plus for Windows version 2020 (VERBI GmbH, Berlin). Categories were developed both inductively and deductively, based on literature review and earlier research. The main categories applied to the entire qualitative material were challenges of, and potentials to improve, RMD care, as well as conceptualization, experiences, opportunities, and barriers in the use of telemedicine in rheumatology. The category system was applied to the entire interview material. At this stage, data collection had already been completed. To ensure traceability, the application of the category system was validated by a member check, where findings were shared and consolidated with the participants in an informal setting. After completion of the structured qualitative content analysis, F.M. and S.M. performed an additional scaled coding, in which opportunities and barriers of telemedicine served as major deductive categories [34]. Codes were scaled to the category "opportunities of telemedicine" if they contained clearly positive expressions (e.g., "this is a good thing", "great opportunity"), whereas codes were scaled as "barriers of telemedicine" if they expressed a clearly negative connotation (e.g., "a negative example would be"). If codes could not be assigned to the scaling categories "opportunities of telemedicine" or "barriers of telemedicine", they were not considered in further analysis. The presentation of the qualitative results focuses on the categories "conceptualization", "opportunities", and "barriers to telemedicine in rheumatology", with the views of patients and professional stakeholders reported separately, within a thematic, cross-categorical structure. For the presentation of the qualitative results, representative quotes were selected from the transcripts, translated verbatim, and included in the text.

\section{Results}

From November 2017 to December 2019, a participatory, mixed-methods study on telemedicine in rheumatology was conducted, consisting of (1) expert interviews ( $n=27)$ with RMD patients and professional stakeholders, (2) a national, paper-based patient survey $(n=766)$, and (3) focus groups $(n=2)$ with patient representatives and rheumatologists.

\subsection{Expert Interviews}

In total, 27 expert interviews (Table 1$)$ were conducted with patients $(n=5)$, rheumatologists $(n=6)$, general practitioners $(n=5)$, a rheumatology assistant $(n=1)$, digital health 
developers $(n=6)$, statutory health insurance representatives $(n=2)$, and representatives of regional association of statutory health insurance physicians $(n=2)$.

Table 1. Expert interviews sample characteristics.

\begin{tabular}{|c|c|c|c|c|c|}
\hline$\#$ & Date & Role/Profession & Age & Gender & TM User $^{1}$ \\
\hline 1 & 28 November 2017 & Rheumatologist & 49 & $\mathrm{~F}$ & Yes \\
\hline 2 & 5 December 2017 & Patient & 51 & $\mathrm{~F}$ & No \\
\hline 3 & 31 January 2018 & Patient & 58 & $\mathrm{~F}$ & No \\
\hline 4 & 8 February 2018 & Patient & 81 & $\mathrm{~F}$ & No \\
\hline 5 & 8 February 2018 & General practitioner & 70 & $\mathrm{~F}$ & No \\
\hline 6 & 22 February 2018 & Rheumatologist & 69 & M & Yes \\
\hline 7 & 7 March 2018 & Digital health developer & 47 & $\mathrm{~F}$ & $\mathrm{~N} / \mathrm{A}$ \\
\hline 8 & 8 March 2018 & Rheumatologist & 45 & $\mathrm{~F}$ & Yes \\
\hline 9 & 23 March 2018 & Rheumatologist & 47 & M & Yes \\
\hline 10 & 28 March 2018 & Digital health developer & 51 & $\mathrm{~F}$ & $\mathrm{~N} / \mathrm{A}$ \\
\hline 11 & 9 April 2018 & General Practitioner & 43 & $\mathrm{~F}$ & Yes \\
\hline 12 & 19 April 2018 & Digital health developer & 50 & $\mathrm{~F}$ & $\mathrm{~N} / \mathrm{A}$ \\
\hline 13 & 23 April 2018 & Patient & 76 & $\mathrm{~F}$ & No \\
\hline 14 & 23 April 2018 & Rheumatologist & 52 & $\mathrm{~F}$ & No \\
\hline 15 & 15 November 2018 & General practitioner & 37 & M & Yes \\
\hline 16 & 21 February 2019 & $\begin{array}{l}\text { Statutory health } \\
\text { insurance representative }\end{array}$ & 45 & F & $\mathrm{N} / \mathrm{A}$ \\
\hline 17 & 18 March 2019 & Digital health developer & 30 & M & $\mathrm{N} / \mathrm{A}$ \\
\hline 18 & 9 May 2019 & Patient & 52 & $\mathrm{~F}$ & Yes \\
\hline 19 & 9 May 2019 & $\begin{array}{l}\text { Statutory health } \\
\text { insurance representative }\end{array}$ & 32 & $\mathrm{~F}$ & $\mathrm{~N} / \mathrm{A}$ \\
\hline 20 & 27 June 2019 & $\begin{array}{l}\text { Representatives of } \\
\text { regional association of } \\
\text { statutory health } \\
\text { insurance physicians }\end{array}$ & 53 & M & $\mathrm{N} / \mathrm{A}$ \\
\hline 21 & 2 July 2019 & General practitioner & 41 & M & Yes \\
\hline 22 & 4 July 2019 & $\begin{array}{l}\text { Digital health developer } \\
\text { Representatives of }\end{array}$ & 66 & M & $\mathrm{N} / \mathrm{A}$ \\
\hline 23 & 11 July 2019 & $\begin{array}{l}\text { regional association of } \\
\text { statutory health } \\
\text { insurance physicians }\end{array}$ & 35 & F & $\mathrm{N} / \mathrm{A}$ \\
\hline 24 & 11 July 2019 & Digital health developer & 65 & $\mathrm{~F}$ & $\mathrm{~N} / \mathrm{A}$ \\
\hline 25 & 17 July 2019 & Rheumatology assistant & 51 & $\mathrm{~F}$ & Yes \\
\hline 26 & 18 July 2019 & Rheumatologist & 34 & M & Yes \\
\hline 27 & 18 July 2019 & General practitioner & 32 & $\mathrm{~F}$ & Yes \\
\hline
\end{tabular}

${ }^{1}$ Question: "Have you ever used telemedicine?; "N/A" (not applicable) refers to interview partners who are involved in direct medical care neither as providers nor as receivers.

\subsubsection{Conceptualization of Telemedicine}

The expert interviews revealed that the term telemedicine is perceived as broad and non-specific, which can be filled with various meanings.

"Telemedicine is comparable to the word digitalization. Everything and nothing. I think telemedicine starts where there is internet access. And I would understand telemedicine as using the technical conditions that we have as efficiently as possible for the benefit of all. And for me, telemedicine is not only the internet access in the medical practice, but also not necessarily the utmost... In other words, performing surgery between two hospitals via a monitor. It's more about using platforms like internet consultations, especially nowadays. So that, the insured also have the opportunity to work with a technical system. In other words, that smartphones are used appropriately. That's how I would actually define telemedicine - well, I think this is somehow wrong. Because telemedicine covers a whole lot of things. And I would say that if you put it very simply, you could actually start telemedicine with the electronic medical letter. This has nothing whatsoever to do with the patient himself, but people send things back and forth to each other without 
using paper. So I would actually say: Telemedicine is everything and nothing, but it definitely starts with the internet connection." (Interview 17, Professional Stakeholder: Health insurance representative, Pos. 19)

Despite the lack of a consistent conceptualization of "telemedicine", the interviewed patients and professional stakeholders described specific opportunities and barriers of telemedicine in rheumatology, which are presented below.

\subsubsection{Patients' Perspectives}

The loss of personal contact and the expected decline in the patient-provider relationship is a major concern of patients. It is a strong driver for acceptance toward telemedicine and has been discussed in various passages of the interview data. Participants emphasized the importance of personal contact, particularly physical-personal contact.

"No, I think it's important. I have to have my doctor right in front of me and he has to have me. Otherwise, a lot of things get lost... for example the way we deal with and trust each other." (Interview 14, Patient, Pos. 110)

Under the premise that physical-personal contact remains unaffected, patients described opportunities for the use of telemedicine in rheumatology. Interviewees highlighted the possibility to receive competent advice even between routine appointments, as well as overcoming travel distances, barriers, and waiting times.

"But I do think that telemedicine is a good thing. You live far away and then suddenly there's something. For example, in my case here. I got a little thing with the skin. (... ) By that it is possible to quickly ask someone competent. 'My God, I actually have to go there tomorrow and now all the joints are swollen and so on'. The rheumatologist would know what to do. He can give you a quick hint: 'Do this or that or this'. So you don't have to go $30 \mathrm{~km}$, wait four hours and then go back $30 \mathrm{~km}$." (Interview 4, Patient, Pos. 125)

These opportunities were contrasted by specific obstacles such as access to, as well as the organization of telemedicine and data security, among others.

"With [name of a video conference service] and the whole thing- Who of the old people up there in Mecklenburg [dense populated region in Germany] or so has the technical equipment? I always ask myself." (Interview 4, Patient, Pos. 125)

"As I said, I see the issue that you can no longer control who gets hold of certain data and what they do with it. (...) Suddenly people find out things, who should not have access to this information. And that's really just the tip of it, because you can't imagine what could be done with such data there." (Interview 2, Patient, Pos. 302)

\subsubsection{Professional Stakeholders' Perspectives}

Professional stakeholders also underlined the importance of physical, face-to-face contact between physicians and patients, emphasizing that the role of telemedicine must be to support, not replace, existing health care services.

"Well, at the end of the day, I consider it as something supportive. It cannot replace the direct contact, the complete direct contact between doctor and patient, it neither can nor should. Because I think I also have to touch, I also have to see personally in front of me, without that it doesn't work." (Interview 10, Professional stakeholder: Rheumatologist, Pos. 93)

Under this premise, various opportunities of telemedicine in rheumatology, but also digital health in general, were mentioned by stakeholders. Yet, interview partners described obstacles that prevent the deployment of telemedicine use cases. One of these is access to adequate internet capacity.

"It is a paradox, that patients who would be most affected by it [telemedicine], patients who live far away from the city, (...) still have white spots in their surroundings, for 
example areas, residential areas where ISDN is available. They don't even have DSL 2000, they don't have anything. And it doesn't matter whether they want to or not, they simply can't hold a video conference." (Interview 22, Professional stakeholder: General practitioner, Pos. 40)

Another obstacle to the use of telemedicine reported by the interviewees was the reimbursement system for medical services in Germany, which does not yet adequately cover the use of telemedicine.

"And I can't bill that at all in the S[ocial] H[ealth] I[nsurance] system, so it's a hobby that I do. But I do have hobbies. Most of my colleagues have hobbies, they know what they can do in their free time. You can't. You can't do hobby activities at work. That is not possible. And that's just telemedicine, unfortunately, that falls into it." (Interview 28, Professional stakeholder: General Practitioner, Pos. 45)

\subsection{Patient Survey}

The questionnaires were handed out in different settings of rheumatology care: (1) working groups of the patient organization German League against Rheumatism ( $n=$ $50)$; (2) outpatient rheumatology practices $(n=17)$; (3) inpatient rheumatology wards $(n$ $=2)$. A total of 5000 questionnaires were distributed. Of those, $766(15 \%)$ were returned. Of the 766 responses, 32 were excluded from further analysis because fewer than half the questions were answered.

Most respondents (72\%) were female. The mean age of the participants was 57 years. Most respondents reported that they were diagnosed with rheumatoid arthritis (46\%), followed by osteoarthritis (24\%), psoriasis arthritis $(14 \%)$, or other conditions (free text form; $14 \%$ ). Most respondents rated their own state of health as bad (40\%) or very bad (7\%) and $45 \%$ rated their own health as "okay". Most of the respondents located their place of residence in rural areas (34\%) and provincial towns (25\%), followed by towns (21\%) and cities (20\%). Participants indicated that they have to travel a median of $10-20 \mathrm{~km}$ to their rheumatology practice. The median reported distance to a general practitioner's office was up to $5 \mathrm{~km}$. Most participants responded that they possess a telephone ( $86 \%$ ), a personal computer $(63 \%)$, a smartphone (57\%), and a mobile phone $(56 \%)$. Overall, $84 \%$ of the surveyed patients indicated that they have internet access at home. Further characteristics of the sample are illustrated in Supplementary Table S2.

\subsubsection{Technology Use in Health Care}

Most survey participants have previously used their phone to contact their physician (79\%); followed by e-mail (23\%) or fax machine (7\%, Figure 2 and Supplementary Table S3). Two respondents indicated that they had a video consultation with their physician.

Almost two-thirds of the participants (66\%) indicated that they had previously searched for information about their rheumatic disease on the internet. Most respondents (79\%, Figure 3) indicated that they were very satisfied, satisfied, or somewhat satisfied with the information provided.

A quarter of the respondents (25\%) stated that they have previously visited the website of their rheumatology practice.

\subsubsection{Telemedicine}

Slightly more than half of the respondents (51\%) reported that they had heard the term "telemedicine" previously before the survey. Further, 38\% of the respondents indicated that they did not wish to try telemedicine (Figure 4). 


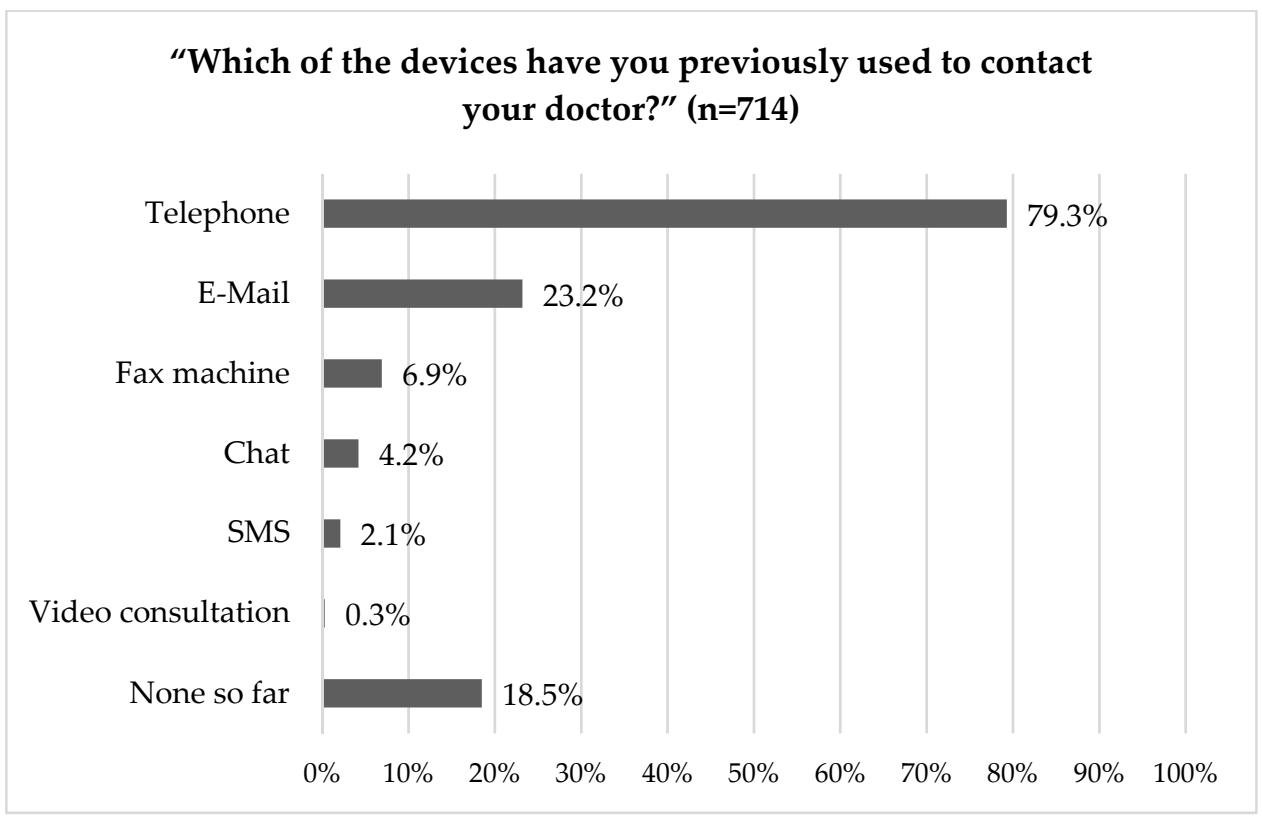

Figure 2. Which of the devices have you previously used to contact your doctor?

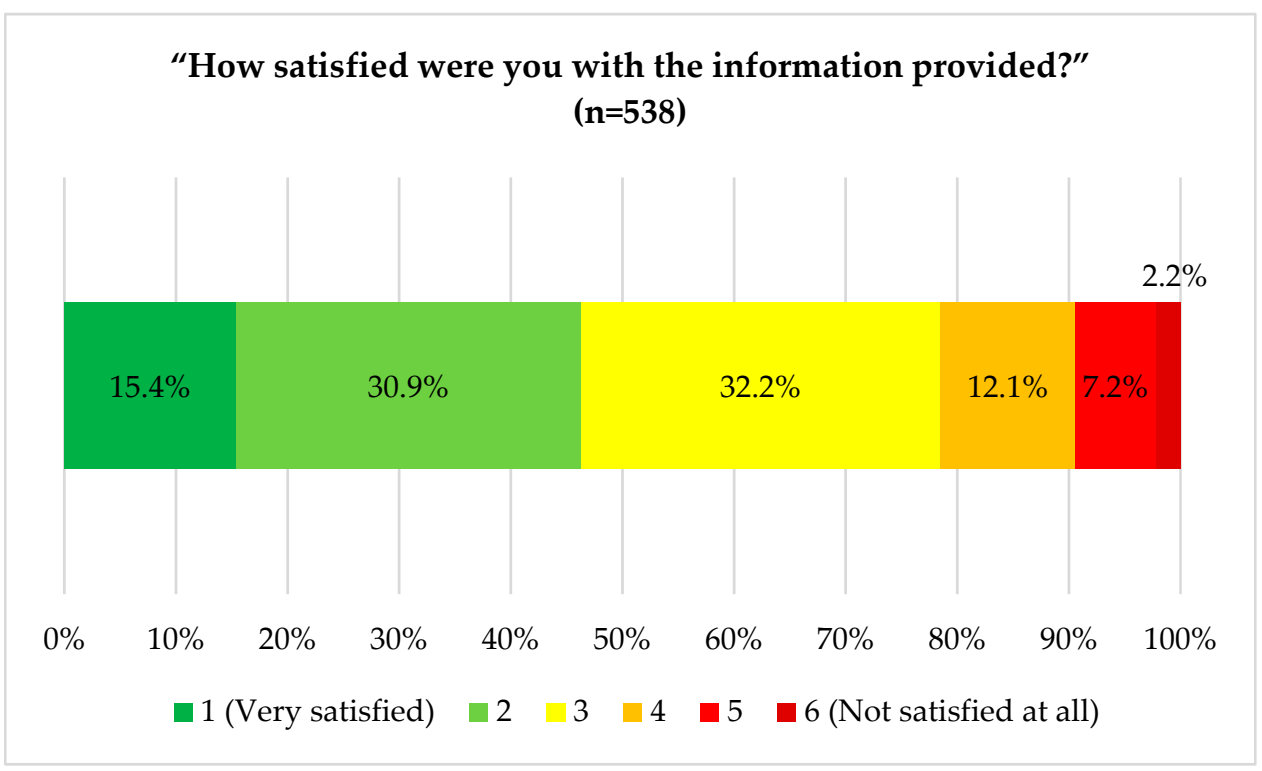

Figure 3. How satisfied were you with the information [on your rheumatic disease] provided [on the internet]?

The item "no personal contact with the doctor" was most frequently quoted as a reason (64\%), followed by "data security" (28\%, Figure 5).

Less than one-third of the survey participants (30\%, Figure 4$)$ indicated that they wanted to try telemedicine. Among these popular use cases were telephone consultations $(60 \%)$, followed by video consultation (35\%), and health care applications (30\%, Figure 6).

Overall, $4 \%$ of the participants responded that they would be willing to pay privately for telemedicine (Table 2), and 21\% of the respondents wanted their rheumatologist to offer them telemedicine services. Moreover, $48 \%$ stated that they wanted their rheumatologist to give them recommendations on digital services. Participants were asked whether they documented their health status: $22 \%$ answered "yes, via paper", and 9\% answered "yes, digitally". 
“Have you heard of the term

'telemedicine' before

participating in this survey?"

$(n=718)$

$4.2 \%$

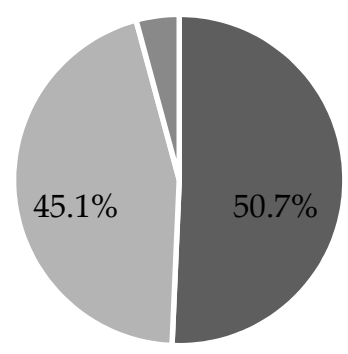

- Yes $\quad$ No $\quad$ I do not know

\section{“Would you like to try}

telemedicine?" $(\mathrm{n}=690)$

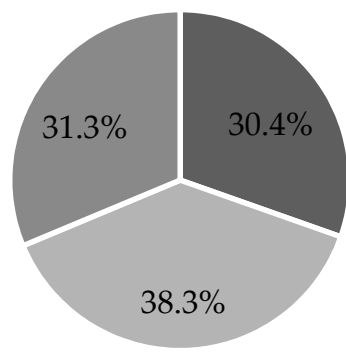

- Yes $\quad$ No $\quad$ I do not know

Figure 4. Have you heard of the term "telemedicine" before participating in this survey?/Would you like to try telemedicine?

"Why do you not want to try telemedicine?" (n=346)

No personal contact to the doctor

Data security

I do not possess the technical equipment

I do not understand the necessary technology

No contact to other patients

$$
\text { Potential costs }
$$

Fear of technology

I do not know.

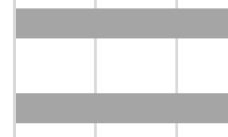

$27.7 \%$

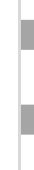<smiles>C1CC2C3CC(C3)C2C1</smiles>

$17.6 \%$

$17.3 \%$

$8.4 \%$

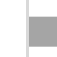

$6.1 \%$

$8.7 \%$

Figure 5. Why do you not want to try telemedicine?

\subsection{Focus Groups}

Two focus groups were held with 10 patient representatives of the German League against Rheumatism and 4 rheumatologists of Working Group Young Rheumatology of the German Society for Rheumatology (DGRh). Both focus groups revealed a homogeneous spectrum of opinions with participants confirming the survey results.

Patient representatives underlined the high relevance of personal contact reported in the survey, which was equated by the discussants with physical-personal contact with the doctor. 


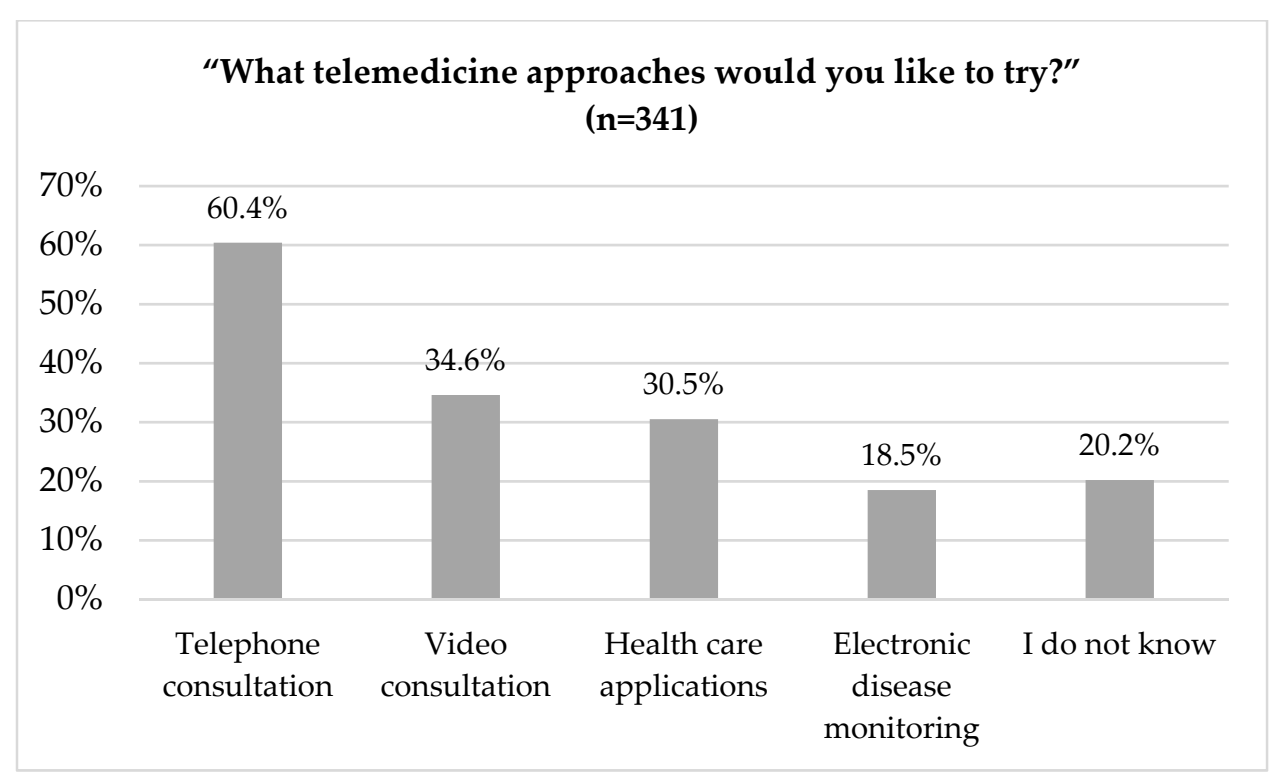

Figure 6. What telemedicine approaches would you like to try?

Table 2. Telemedicine.

Total

\begin{tabular}{lr}
\hline $\begin{array}{l}\text { “Would you like your rheumatologist to } \\
\text { offer you telemedicine services?” }\end{array}$ & 663 \\
\hline Yes & $139(21.0 \%)$ \\
\hline No & $286(43.1 \%)$ \\
\hline I do not know & $238(35.9 \%)$ \\
\hline “Would you like your rheumatologist to give & 661 \\
you recommendations on digital services?" & $320(48.4 \%)$ \\
\hline Yes & $211(31.9 \%)$ \\
\hline No & $130(19.7 \%)$ \\
\hline I do not know & 675 \\
\hline “Would you be willing to pay privately for & $25(3.7 \%)$ \\
\hline telemedicine services?” & $518(76.7 \%)$ \\
\hline Yes & $132(19.6 \%)$ \\
\hline No & 662 \\
\hline I do not know & $158(23.9 \%)$ \\
\hline “Do you document your health status?” & $59(8.8 \%)$ \\
\hline Yes, via paper & $445(67.2 \%)$ \\
\hline Yes, digitally & \\
\hline No & \\
\hline
\end{tabular}

"Discussant: Well, personal contact with the doctor is important. And not taking a picture and sending it somewhere. For me, personal contact is most important. Interviewer: And personal contact means you want to be in the same room with the doctor? Discussant: Yes." (Focus group 2, Patient representative, Pos. 174)

Patient representatives discussed the potentials and risks of telemedicine in their personal health care. Participants were particularly averse to the use of telemedicine services if they were not applied by their own doctor, on the basis of an existing patientdoctor relationship. 
"Then I also imagine an overload for the doctor. Because he now also has patients who he doesn't know. That would be irresponsible, because he doesn't see the whole person and so on. I don't want to imagine that at all. So at the very most, if you are under a doctor's care and he knows you, you may then also ask a question by phone or by video or by telemedicine. For a doctor who has never seen me or so, I would not actually agree with that. (Focus group 2, Patient representative, Pos. 178)

A discussion point that complements the survey results is the organizational integration of telemedicine into medical routines in the context of scarce time resources.

"I' $m$ interested in the organizational side of things. When I make a phone call now, where do I actually end up? Is it a doctor who has office hours there, who only does telemedicine? Because when I arrive at my doctor's office, he doesn't have any time, he has to see his patients. He can't focus on me. I do not see it." (Focus group 2, Patient representative, Pos. 116)

Rheumatologists expressed a positive attitude toward telemedicine in the focus group, highlighting the potential of telemedicine as a support of existing care structures.

"Perhaps telemedicine can then be seen more or less as a digital safety or support network, so to speak. We as physicians are more or less automatically notified of potential problems thus we can react as promptly as possible in the consultation." (Focus group 1, Rheumatologists Pos. 40)

Scarce time resources and practical integration of telemedicine into medical routines were also discussed in the focus group with the rheumatologists. As resources are already limited, telemedicine should not simply be appended to the existing medical tasks.

"We are all open-minded, but nevertheless the doctors have no time for it... to practice telemedicine in addition to their normal office hours. It only works if retired doctors are brought on board again. So from there, the topic of time savings, I think you have to carefully consider for whom this is a time saving." (Focus group 1, Rheumatologists, Pos. 26)

Overall, the results of the different methodological study parts coincide and complement each other, with qualitative findings allowing deeper interpretation of the quantitative data. Table 3 lists the key findings on opportunities and barriers of telemedicine implementation in rheumatology from each workgroup.

Table 3. Key findings in opportunities and barriers of telemedicine in rheumatology.

\begin{tabular}{|c|c|c|c|c|c|}
\hline & & & Opportunities & & Barriers \\
\hline 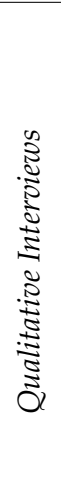 & 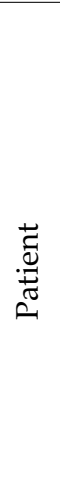 & $>$ & $\begin{array}{l}\text { Patients appreciated the } \\
\text { potential of telemedicine to } \\
\text { overcome space and time in their } \\
\text { personal rheumatology care } \\
\text { Patients expected telemedicine } \\
\text { to reduce physical barriers and } \\
\text { to contribute to accessibility and } \\
\text { immediacy of health care } \\
\text { Patients expected telemedicine } \\
\text { to reduce waiting times \& } \\
\text { contribute to quick medical } \\
\text { assessment in case of symptom } \\
\text { changes }\end{array}$ & $>$ & $\begin{array}{l}\text { Patients perceived the loss of } \\
\text { personal physical contact to the } \\
\text { physicians as main barrier of } \\
\text { telemedicine } \\
\text { Patients expected deterioration of } \\
\text { the patient-doctor relationship due } \\
\text { to telemedicine } \\
\text { Patients reported data security, } \\
\text { lack of technical equipment \& } \\
\text { knowledge as further barriers of } \\
\text { telemedicine implementation }\end{array}$ \\
\hline
\end{tabular}


Table 3. Cont.

\begin{tabular}{|c|c|c|c|c|}
\hline & & & Opportunities & Barriers \\
\hline 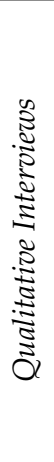 & 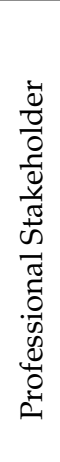 & $>$ & $\begin{array}{l}\text { Professional stakeholders } \\
\text { expected telemedicine to } \\
\text { contribute to effective allocation } \\
\text { of resources in rheumatology } \\
\text { care (e.g. by replacing routine } \\
\text { appointments) } \\
\text { According to professional } \\
\text { stakeholders, telemedicine could } \\
\text { increase treatment continuity by } \\
\text { enabling effective disease } \\
\text { monitoring \& tight control }\end{array}$ & $\begin{array}{l}\text { Professional stakeholders } \\
\text { identified the absence of physical } \\
\text { examination as a main } \\
\text { disadvantage of telemedicine in } \\
\text { rheumatology care } \\
\text { Professional stakeholders } \\
\text { recognized practical challenges as } \\
\text { barriers of telemedicine: } \\
\text { organization of telemedicine in } \\
\text { clinical routines, poor } \\
\text { remuneration \& lack of digital } \\
\text { infrastructure }\end{array}$ \\
\hline 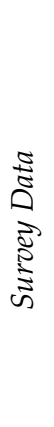 & $\stackrel{\overrightarrow{0}}{\stackrel{\vec{J}}{\sigma}}$ & $>$ & $\begin{array}{l}\text { There has been moderate interest } \\
\text { in further information on digital } \\
\text { services provided by the } \\
\text { rheumatologists } \\
\text { Most patients indicated that they } \\
\text { use the internet as a source of } \\
\text { health information } \\
\text { Most patients indicated that they } \\
\text { possess the equipment to use } \\
\text { telemedicine and have internet } \\
\text { access at their home }\end{array}$ & $\begin{array}{l}>\quad \text { Patients reported the loss of } \\
\text { personal contact with the doctor as } \\
\text { a main concern associated to } \\
\text { telemedicine } \\
>\quad \text { Survey data suggests, that } \\
\text { telemedicine services are not } \\
\text { available/are not offered in most } \\
\text { medical practices } \\
\text { Patients reported lack of } \\
\text { information on digital services }\end{array}$ \\
\hline \multirow{2}{*}{ 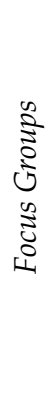 } & 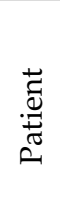 & $>$ & $\begin{array}{l}\text { Patients supported telemedicine } \\
\text { as an addition to physical } \\
\text { consultations if the physician } \\
\text { and patient are already } \\
\text { acquainted with each other }\end{array}$ & $\begin{array}{l}\text { Patients perceived the practical } \\
\text { implementation of telemedicine } \\
\text { services in medical practice as } \\
\text { uncertain. }\end{array}$ \\
\hline & 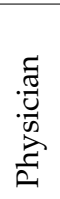 & $>$ & $\begin{array}{l}\text { Rheumatologists perceived } \\
\text { telemedicine as additional safety } \\
\text { and support for close monitoring } \\
\text { and to provide patients with the } \\
\text { best possible care }\end{array}$ & $\begin{array}{l}\text { Telemedicine could tie up } \\
\text { additional time resources that are } \\
\text { already scarce in rheumatology }\end{array}$ \\
\hline
\end{tabular}

\section{Discussion}

This mixed-methods study combines findings from expert interviews, a patient survey, and focus groups on telemedicine acceptance, barriers, and opportunities in rheumatology care, conducted shortly before the COVID-19 outbreak. The results of our survey indicate patients' heterogeneous opinions on telemedicine in RMD care-namely, the loss of personal contact with the doctor was the main reason for rejection, and telephone consultations were the most preferred telemedicine by patients. Furthermore, the results point to information needs regarding telemedicine implementation in RMD care. Qualitative findings substantiate these results, as interviewed patient representatives were generally amenable to the use of telemedicine and associate, for example, time savings or the reduction in travel distances to RMD care with telemedicine. However, according to the survey data, patient representatives identified major barriers as missing technical infrastructure, potential data insecurity, and, again, the loss of personal contact with the doctor, which, in the focus groups, was underlined to be meant as the physical-personal contact. Professional stakeholders who participated in the qualitative study modules considered telemedicine as a potential safety measure in RMD care delivery and a resource for achieving higher continuity of care. However, organizational challenges and the lack of digital equipment and infrastructure in Germany impede telemedicine implementation, according to the stakeholders. Plus, time resources to implement and use telemedicine in the first step are missing, which, combined with poor reimbursement modalities, leaves telemedical care 
unprofitable or, as one interviewed physician referred to it, "a hobby". Recommendations to overcome barriers to telemedicine implementation in rheumatology are illustrated in Supplementary Table S4.

Compared with German rheumatologists and general practitioners, our survey results illustrate that patients tend to be reluctant to use telemedicine [23]. Overall, $62 \%$ of the physicians surveyed stated that they wanted to try telemedicine, twice as much as the patients surveyed in this study. Physicians rated their own knowledge [23] and experience [35] in telemedicine as low. The results of the patient survey, however, indicate that patients wanted advice from their rheumatologists on digital health. To meet these expectations, further and specific training opportunities in the use of telemedicine and digital health are highly needed [36,37].

The lack of face-to-face contact with physicians, often equated with physical contact, remains a key issue regarding telemedicine implementation for patients and professionals alike. Patients fear a deterioration of the patient-doctor relationship due to telemedicine. Physicians mentioned missing physical exams while using telemedicine. This raises the fundamental concern of poorer rheumatology care via telemedicine-despite existing evidence that telerheumatology can achieve similar outcomes as conventional care [38] and high satisfaction rates on patient-physician communication via telemedicine reported by patients [39]. Although the effectiveness of telerheumatology is gradually being demonstrated $[20,38,40,41]$, the perspectives and concerns by potential users have to be continuously included in digital health care implementation. An example would be an individual assessment to determine which patients and providers are eligible for which model of telemedicine care, by reflecting predisposing, facilitating, and reinforcing factors [42]. Kulcsar et al. reported that a telemonitoring approach is appropriate to $81 \%$ of RMD patients and propose a triage mechanism to ensure that patients are appropriately paired to the proper visit type in the future [42]. Coincidingly, our results suggest that patients with a confirmed diagnosis, stable disease course, and having a close and trusting patient-doctor relationship are particularly suitable for telemedicine. Likewise, we believe a complementary, need-adapted, and personalized combined virtual/on-site care approach combines the best from two worlds. This allows the potential of telemedicine to be utilized but still preserves opportunities for physical examination and intervention in the event of miscommunication. Thus, the fact that telemedicine does not replace face-to-face care but complements it [37] might lead to an increase in acceptance and also enable previously skeptical persons to gain first experiences in the use of telerheumatology.

Our survey data revealed that patients were mainly using the telephone for physician communication, and interestingly, only $2 / 714$ indicated that they had a video consultation with their physician. More patients preferred the telephone to video consultation, consistent with previous studies that identified the telephone as the preferred means of contact with rheumatologists. [43,44]. In contrast to a previous German survey with RMD patients $(n=193)$, conducted at an outpatient clinic of a major German university hospital in 2018/2019 [43], significantly fewer RMD patients possessed a smartphone (57\%). This lack of technical equipment was confirmed by patients and rheumatologists in the qualitative part as a barrier to telemedicine usage. Contrastingly, Kernder et al. recently reported that technical equipment represented only a minor barrier for German RMD patients and rheumatologists in the introduction of digital health applications (DHA) [26]. These authors identified the lack of information and evidence as the main barriers for DHA. The latter work was based on post-COVID 19 outbreak data derived from a web-based survey, likely introducing a selection bias. Our survey participants were on average 8 years older. Nevertheless, the majority of patients stated to have an internet connection at home.

Similar to previous work [37,43], we identified the increased flexibility, especially concerning time and location, as the main advantages of telerheumatology. Plus, patients emphasized the reduction in unnecessary routine, face-to-face appointments as a potential of telemedicine in rheumatology. In line with Kernder's study, the majority of rheumatologists and patients agreed on implementing virtual visits for follow-up appointments 
in stable disease conditions [26]. Importantly, a randomized, controlled trial showed that telemedicine follow-up can achieve similar disease control to a conventional outpatient follow-up [38].

All data reported in this study were collected shortly before the COVID-19 outbreak. The pandemic, infection control measures, and changes in traditional health care delivery, however, have impacted patient and professional stakeholder perspectives on telemedicine globally [45], locally [25], and specifically in rheumatology care as well [26,46], resulting in massive uptake of telemedicine and digital health care. The necessity of using telemedicine to reduce contacts and infection transmission may have led many to their first experiences with telemedicine and might have contributed to the increased acceptance of telemedicine. Since the beginning of 2021, however, these figures have been declining again [27]. Lacking digital infrastructure in Germany, concerns related to patient-doctor relationship and data security, scarce time resources to implement telemedicine, and even regulatory barriers are aspects that remain unchanged. However, these must be targeted to yield sustainable telemedicine use, in order to alleviate resources of health care practitioners to provide appropriate care for rising numbers of RMD patients [47]. The results of this study should serve as a reference for comparable studies, as further research, especially a replication of our research to capture the impact of COVID-19 and measure the progress of digital transformation in rheumatology, is highly needed.

There are limitations to our study. Following an exploratory, participatory, mixedmethods approach, we deliberately defined telemedicine broadly in order to explore telemedicine concepts in rheumatology from the user perspectives. However, this also may have led to reduced comparability of the qualitative results. In consultation with the patient organization, we aimed to provide a questionnaire that was understandable for all potential participants-digitally skilled or not. In consequence, the general acceptance of patients toward telemedicine in rheumatology is well covered in the survey results. However, developmental and treatment-related issues of telemedicine use, such as mode (asynchronous vs. synchronous) or specific telemedicine approaches, were only outlined in the qualitative data and need to be examined in subsequent studies. In addition, the study information sent with the questionnaire could be a source of learning bias [48]. It included a definition of telemedicine with two examples of telemedicine use cases (video and telephone consultation) and thus might have influenced the responses.

Interviews were conducted over a 21-month period (November 2017-July 2019). The response rate to the patient survey was comparatively low, at 15\% [49], with a higher response among inpatient facilities (96\%/33\% of the total questionnaires) than among outpatient providers $(11 \% / 54 \%$ of the total questionnaires) or patient organization workgroups (14\%/13\% of the total questionnaires). This is attributable to the distribution strategy and potentially could have been positively influenced by reminders or incentives. The low and uneven response may also be associated with several types of bias: nonresponse bias, selection bias, and social desirability bias. To overcome an additional selection bias, we chose a paper-based survey in favor of an electronic approach [49]. No definite recruitment strategy (e.g., maximum variation sampling) was pursued to collect the qualitative data. This could be associated with self-selection bias. The two focus groups were attended exclusively by patient representatives or rheumatologists. This resulted in homogeneous responses. Diversification might have provided further insights. We decided against this to reduce social desirability bias.

To the best of our knowledge, we performed the first participatory, multi-perspective, mixed-methods study on telemedicine in adult rheumatology. To ensure a representative sample, patient representatives were also involved at all stages and patient inclusion was extensive (patient organization, outpatient, inpatient setting). The mixed-methods approach provides comprehensive insights into the perspective of RMD patients and key stakeholders in rheumatology care. The results of our study demonstrate the great importance of trustful patient-physician relationships in rheumatology, based on physical-personal contacts, which might be complemented but not replaced by telemedicine. Our findings also 
revealed RMD patient demands for further information and knowledge on digital health that rheumatologists must meet as their discipline faces ongoing digital transformation.

\section{Conclusions}

Based on pre-COVID data, we identified barriers and opportunities to further support the design and implementation of telemedicine in rheumatology care. RMD patients value the physical-personal contact with their rheumatologists and fear a negative impact on the patient-doctor relationship with the introduction of telemedicine to their personal health care. Thus, many RMD patients reject the use of telemedicine. On the other hand, participants perceive immediacy of care, overcoming distances, and efficient allocation of scarce resources as opportunities for telemedicine. Both the qualitative and the survey data revealed that organizational and infrastructural barriers have to be overcome, and information needs have to be met in order to implement telemedicine effectively and sustainably in rheumatology care.

Supplementary Materials: The following are available online at https://www.mdpi.com/article/ 10.3390/ijerph182413127/s1, Table S1: Qualitative Interviews: Interview guide-translated from German, Table S2: Survey sample characteristics, Table S3: Technology use in health care, Table S4: Recommendations to overcome barriers to telemedicine implementation in rheumatology.

Author Contributions: All authors were involved in drafting the article and critically revising it for important intellectual content, and all authors approved the final version to be submitted for publication. F.M. had full access to all the data in the study and takes responsibility for the integrity of the data and the accuracy of the data analysis. Study conception and design, F.M., W.M., M.W.; Acquisition of data: F.M., W.M., J.K., M.K., A.H. and M.W.; analysis and interpretation of data, F.M., J.K., S.M., M.K., W.M., A.H., J.S., N.V., M.H. and M.W. All authors have read and agreed to the published version of the manuscript.

Funding: Financial support was provided by Novartis Pharma GmbH. Novartis had no role in the study design or in the collection, analysis, or interpretation of the data; the writing of the manuscript; or the decision to submit the manuscript for publication. Publication of this article was not contingent upon approval by Novartis. Publication funding was provided by the MHB Open Access Publication Fund supported by the German Research Association (DFG).

Institutional Review Board Statement: The ethics committee of the Brandenburg Medical School stated that no ethical approval consent was necessary due to the non-interventional study design. There was no risk involved in participating in this study. All study activities were conducted according to the guidelines of the Declaration of Helsinki.

Informed Consent Statement: Interview and focus group participants provided written consent. Survey participants were informed with a cover letter and agreed to the use of their data by returning the questionnaires.

Data Availability Statement: All data relevant to the study are included in the article. For further questions regarding the reuse of data, please contact the corresponding author (felix.muehlensiepen@mhbfontane.de).

Acknowledgments: We acknowledge funding by the MHB Open Access Publication Fund supported by the German Research Association (DFG). We would like to thank the participants and supporters of TeleRheumaBB. We especially thank the Deutsche Rheuma Liga Landesvertretung Brandenburg for their support in the development and distribution of the questionnaire. We also owe special gratitude to KV Consult- und Managementgesellschaft $\mathrm{mbH}$, which initiated the study. The present work is part of the PhD theses of F.M. (AGEIS, Universite Grenoble Alpes, Grenoble, France).

Conflicts of Interest: F.M. has received financial research support from Novartis. J.K. has received financial research support from Novartis, Sanofi, UCB, Thermo Fisher. S.M. has no potential conflict of interest. M.K. has received financial research support from Novartis and Sanofi. W.M. has received financial research support from Novartis. A.H. has no potential conflict of interest. J.S. has no potential conflict of interest. N.V. has no potential conflict of interest. M.H. has no potential conflict of interest. M.W. has received financial appropriation (research, advice, lectures) from AbbVie, Amgen, 
BMS, Berlin Chemie, Galapagos, Gilead, GSK, Hexal, Janssen, Medac, Mylan, Novartis, Pfizer, Sanofi, and UCB.

\section{References}

1. Sebbag, E.; Felten, R.; Sagez, F.; Sibilia, J.; Devilliers, H.; Arnaud, L. The world-wide burden of musculoskeletal diseases: A systematic analysis of the World Health Organization Burden of Diseases Database. Ann. Rheum. Dis. 2019, 78, 844-848. [CrossRef]

2. Krusche, M.; Sewerin, P.; Kleyer, A.; Mucke, J.; Vossen, D.; Morf, H. [Specialist training quo vadis?]. Z. Rheumatol. 2019, 78, 692-697. [CrossRef] [PubMed]

3. Al Maini, M.; Adelowo, F.; Al Saleh, J.; Al Weshahi, Y.; Burmester, G.R.; Cutolo, M.; Flood, J.; March, L.; McDonald-Blumer, H.; Pile, K.; et al. The global challenges and opportunities in the practice of rheumatology: White paper by the World Forum on Rheumatic and Musculoskeletal Diseases. Clin. Rheumatol. 2015, 34, 819-829. [CrossRef] [PubMed]

4. Sørensen, J.; Hetland, M.L. Diagnostic delay in patients with rheumatoid arthritis, psoriatic arthritis and ankylosing spondylitis: Results from the Danish nationwide DANBIO registry. Ann. Rheum. Dis. 2015, 74, e12. [CrossRef]

5. Quinn, M.A.; Emery, P. Window of opportunity in early rheumatoid arthritis: Possibility of altering the disease process with early intervention. Clin. Exp. Rheumatol. 2003, 21, S154-S157.

6. Mitra, A.; Veerakone, R.; Li, K.; Nix, T.; Hashikawa, A.; Mahajan, P. Telemedicine in paediatric emergency care: A systematic review. J. Telemed. Telecare 2021, 1357633X211010106. [CrossRef]

7. Battineni, G.; Sagaro, G.G.; Chintalapudi, N.; Amenta, F. The Benefits of Telemedicine in Personalized Prevention of Cardiovascular Diseases (CVD): A Systematic Review. J. Pers. Med. 2021, 11, 658. [CrossRef]

8. da Fonseca, M.H.; Kovaleski, F.; Picinin, C.T.; Pedroso, B.; Rubbo, P. E-Health Practices and Technologies: A Systematic Review from 2014 to 2019. Healthcare (Basel) 2021, 9, 1192. [CrossRef]

9. May, S.; Jonas, K.; Fehler, G.V.; Zahn, T.; Heinze, M.; Muehlensiepen, F. Challenges in current nursing home care in rural Germany and how they can be reduced by telehealth-An exploratory qualitative pre-post study. BMC Health Serv. Res. 2021, 21, 1-10. [CrossRef]

10. Labarca, G.; Schmidt, A.; Dreyse, J.; Jorquera, J.; Barbe, F. Telemedicine interventions for CPAP adherence in obstructive sleep apnea patients: Systematic review and meta-analysis. Sleep Med. Rev. 2021, 60, 101543. [CrossRef] [PubMed]

11. Chan, R.J.; Crichton, M.; Crawford-Williams, F.; Agbejule, O.A.; Yu, K.; Hart, N.H.; de Abreu Alves, F.; Ashbury, F.D.; Eng, L.; Fitch, M.; et al. The efficacy, challenges, and facilitators of telemedicine in post-treatment cancer survivorship care: An overview of systematic reviews. Ann. Oncol. Off. J. Eur. Soc. Oncol. 2021, 32, 1552-1570. [CrossRef] [PubMed]

12. World Medical Association. Statement on the Ethics of Telemedicine. 2018. Available online: https://www.wma.net/policiespost/wma-statement-on-the-ethics-of-telemedicine/ (accessed on 8 March 2021).

13. World Health Organisation. Telemedicine. Opportunities and Developments in Member States. Report on the Second Global Survey on eHealth. Global Observatory for eHealth Series-Volume 2. Available online: https://www.who.int/goe/publications/ goe_telemedicine_2010.pdf (accessed on 25 November 2021).

14. Snoswell, C.L.; Chelberg, G.; De Guzman, K.R.; Haydon, H.H.; Thomas, E.E.; Caffery, L.J.; Smith, A.C. The clinical effectiveness of telehealth: A systematic review of meta-analyses from 2010 to 2019. J. Telemed. Telecare 2021, 1357633x211022907. [CrossRef] [PubMed]

15. Rasmussen, M.B.; Frost, L.; Stengaard, C.; Brorholt-Petersen, J.U.; Dodt, K.K.; Søndergaard, H.M.; Terkelsen, C.J. Diagnostic performance and system delay using telemedicine for prehospital diagnosis in triaging and treatment of STEMI. Heart (Br. Card. Soc.) 2014, 100, 711-715. [CrossRef] [PubMed]

16. Koehler, F.; Koehler, K.; Deckwart, O.; Prescher, S.; Wegscheider, K.; Kirwan, B.A.; Winkler, S.; Vettorazzi, E.; Bruch, L.; Oeff, M.; et al. Efficacy of telemedical interventional management in patients with heart failure (TIM-HF2): A randomised, controlled, parallel-group, unmasked trial. Lancet (Lond. Engl.) 2018, 392, 1047-1057. [CrossRef]

17. Russo, J.E.; McCool, R.R.; Davies, L. VA Telemedicine: An Analysis of Cost and Time Savings. Telemed. J. E-Health Off. J. Am. Telemed. Assoc. 2016, 22, 209-215. [CrossRef] [PubMed]

18. Sayani, S.; Muzammil, M.; Saleh, K.; Muqeet, A.; Zaidi, F.; Shaikh, T. Addressing cost and time barriers in chronic disease management through telemedicine: An exploratory research in select low- and middle-income countries. Adv. Chronic Dis. 2019, 10, 2040622319891587. [CrossRef]

19. Ward, I.M.; Schmidt, T.W.; Lappan, C.; Battafarano, D.F. How Critical is Tele-Medicine to the Rheumatology Workforce? Arthritis Care Res. 2016, 68, 1387-1389. [CrossRef]

20. Rezaian, M.M.; Brent, L.H.; Roshani, S.; Ziaee, M.; Sobhani, F.; Dorbeigi, A.; Fatehi, Z.; Hardy, J.; Ragati Haghi, Y.; Maghsoudi, T.; et al. Rheumatology Care Using Telemedicine. Telemed. J. E-Health Off. J. Am. Telemed. Assoc. 2020, 26, 335-340. [CrossRef]

21. Welcker, M.; Mühlensiepen, F.; Knitza, J.; Popp, F.; Aries, P. Digitalization in rheumatological practice. Z. Rheumatol. 2021, 80, 835-845. [CrossRef] 
22. Najm, A.; Nikiphorou, E.; Kostine, M.; Richez, C.; Pauling, J.D.; Finckh, A.; Ritschl, V.; Prior, Y.; Balážová, P.; Stones, S.; et al. EULAR points to consider for the development, evaluation and implementation of mobile health applications aiding selfmanagement in people living with rheumatic and musculoskeletal diseases. RMD Open 2019, 5, e001014. [CrossRef] [PubMed]

23. Muehlensiepen, F.; Knitza, J.; Marquardt, W.; Engler, J.; Hueber, A.; Welcker, M. Acceptance of Telerheumatology by Rheumatologists and General Practitioners in Germany: Nationwide Cross-sectional Survey Study. J. Med. Internet Res. 2021, 23 , e23742. [CrossRef]

24. Health Innovation Hub. DVG_A Summary of Germany's New Law for Digital Health Applications. Available online: https: / / hih-2025.de/dvg-a-summary-of-germanys-new-law-for-digital-health-applications / (accessed on 25 November 2021).

25. Bruch, D.; Muehlensiepen, F.; Alexandrov, A.; Konstantinova, Y.; Voß, K.; Ronckers, C.; Neugebauer, E.; May, S. The impact of the COVID-19 pandemic on professional practice and patient volume in medical practices: A survey among German physicians and psychotherapists. Z. Evid. Qual. Gesundhwes 2021, 166, 27-35. [CrossRef]

26. Kernder, A.; Morf, H.; Klemm, P.; Vossen, D.; Haase, I.; Mucke, J.; Meyer, M.; Kleyer, A.; Sewerin, P.; Bendzuck, G.; et al. Digital rheumatology in the era of COVID-19: Results of a national patient and physician survey. RMD Open 2021, 7, e001548. [CrossRef]

27. Zentral Institut für Kassenärztliche Versorgung in Deutschland. With Second Corona Lockdown Starting in November 2020, Another Significant Decline in Outpatient Treatment Cases / Physician Practices with Vaccination Record against Influenza and Pneumococci. Available online: https:/ / www.zi.de/presse/presseinformationen/19-april-2021 (accessed on 25 November 2021).

28. Creswell, J.W. Research Design: Qualitative, Quantitative, and Mixed Methods Approaches, 2nd ed.; Sage: Thousand Oaks, CA, USA, 2003.

29. World Medical Association. World Medical Association Declaration of Helsinki: Ethical principles for medical research involving human subjects. JAMA 2013, 310, 2191-2194. [CrossRef] [PubMed]

30. Bogner, A.; Littig, B.; Menz, W. Interviewing Experts; Palgrave Macmillan: London, UK, 2009.

31. Robinson, O.C. Sampling in Interview-Based Qualitative Research: A Theoretical and Practical Guide. Qual. Res. Psychol. 2014, 11, 25-41. [CrossRef]

32. Krueger, R.A.; Casey, M.A. Focus Groups: A Practical Guide for Applied Research, 3rd ed.; Sage Publications: Thousand Oaks, CA, USA, 2015.

33. Kuckartz, U. Qualitative Inhaltsanalyse, 4th ed.; Beltz Juventa: Weinheim, Germany, 2018.

34. Kurkowski, S.; Radon, J.; Vogt, A.R.; Weber, M.; Stiel, S.; Ostgathe, C.; Heckel, M. Hospital end-of-life care: Families' free-text notes. BMJ Support. Palliat. Care 2020. [CrossRef]

35. Matsumoto, R.A.; England, B.R.; Mastarone, G.; Richards, J.S.; Chang, E.; Wood, P.R.; Barton, J.L. Rheumatology Clinicians' Perceptions of Telerheumatology Within the Veterans Health Administration: A National Survey Study. Mil. Med. 2020, 185, e2082-e2087. [CrossRef] [PubMed]

36. Nazeha, N.; Pavagadhi, D.; Kyaw, B.M.; Car, J.; Jimenez, G.; Car, L.T. A Digitally Competent Health Workforce: Scoping Review of Educational Frameworks. J. Med. Internet Res. 2020, 22, e22706. [CrossRef] [PubMed]

37. Mühlensiepen, F.; Kurkowski, S.; Krusche, M.; Mucke, J.; Prill, R.; Heinze, M.; Welcker, M.; Schulze-Koops, H.; Vuillerme, N.; Schett, G.; et al. Digital Health Transition in Rheumatology: A Qualitative Study. Int. J. Environ. Res. Public Health 2021, 18, 2636. [CrossRef]

38. de Thurah, A.; Stengaard-Pedersen, K.; Axelsen, M.; Fredberg, U.; Schougaard, L.M.V.; Hjollund, N.H.I.; Pfeiffer-Jensen, M.; Laurberg, T.B.; Tarp, U.; Lomborg, K.; et al. Tele-Health Followup Strategy for Tight Control of Disease Activity in Rheumatoid Arthritis: Results of a Randomized Controlled Trial. Arthritis Care Res. 2018, 70, 353-360. [CrossRef]

39. Agha, Z.; Schapira, R.M.; Laud, P.W.; McNutt, G.; Roter, D.L. Patient satisfaction with physician-patient communication during telemedicine. Telemed. J. E-Health Off. J. Am. Telemed. Assoc. 2009, 15, 830-839. [CrossRef] [PubMed]

40. Piga, M.; Cangemi, I.; Mathieu, A.; Cauli, A. Telemedicine for patients with rheumatic diseases: Systematic review and proposal for research agenda. Semin. Arthritis Rheum. 2017, 47, 121-128. [CrossRef] [PubMed]

41. McDougall, J.A.; Ferucci, E.D.; Glover, J.; Fraenkel, L. Telerheumatology: A Systematic Review. Arthritis Care Res. 2017, 69, 1546-1557. [CrossRef]

42. Kulcsar, Z.; Albert, D.; Ercolano, E.; Mecchella, J.N. Telerheumatology: A technology appropriate for virtually all. Semin. Arthritis Rheum. 2016, 46, 380-385. [CrossRef] [PubMed]

43. Knitza, J.; Simon, D.; Lambrecht, A.; Raab, C.; Tascilar, K.; Hagen, M.; Kleyer, A.; Bayat, S.; Derungs, A.; Amft, O.; et al. Mobile Health Usage, Preferences, Barriers, and eHealth Literacy in Rheumatology: Patient Survey Study. JMIR mHealth uHealth 2020, 8 , e19661. [CrossRef] [PubMed]

44. Edwards, L.; Thomas, C.; Gregory, A.; Yardley, L.; O'Cathain, A.; Montgomery, A.A.; Salisbury, C. Are people with chronic diseases interested in using telehealth? A cross-sectional postal survey. J. Med. Internet Res. 2014, 16, e123. [CrossRef]

45. Bhaskar, S.; Bradley, S.; Chattu, V.K.; Adisesh, A.; Nurtazina, A.; Kyrykbayeva, S.; Sakhamuri, S.; Yaya, S.; Sunil, T.; Thomas, P.; et al. Telemedicine Across the Globe-Position Paper From the COVID-19 Pandemic Health System Resilience PROGRAM (REPROGRAM) International Consortium (Part 1). Front. Public Health 2020, 8, 556720. [CrossRef]

46. Mehta, B.; Jannat-Khah, D.; Fontana, M.A.; Moezinia, C.J.; Mancuso, C.A.; Bass, A.R.; Antao, V.C.; Gibofsky, A.; Goodman, S.M.; Ibrahim, S. Impact of COVID-19 on vulnerable patients with rheumatic disease: Results of a worldwide survey. RMD Open 2020, 6, e001378. [CrossRef] 
47. Miloslavsky, E.M.; Bolster, M.B. Addressing the rheumatology workforce shortage: A multifaceted approach. Semin. Arthritis Rheum. 2020, 50, 791-796. [CrossRef]

48. Choi, B.C.; Pak, A.W. A catalog of biases in questionnaires. Prev. Chronic Dis. 2005, 2, A13.

49. Hohwü, L.; Lyshol, H.; Gissler, M.; Jonsson, S.H.; Petzold, M.; Obel, C. Web-based versus traditional paper questionnaires: A mixed-mode survey with a Nordic perspective. J. Med. Internet Res. 2013, 15, e173. [CrossRef] [PubMed] 